\title{
Aging and Language: Maintenance of Morphological Representations in Older Adults
}

\author{
Phaedra Royle ${ }^{1,2 *}$, Karsten Steinhauer ${ }^{2,3}$, Émie Dessureault ${ }^{1}$, Alexandre C. Herbay ${ }^{2,3}$ and \\ Simona M. Brambati ${ }^{4}$
}

${ }^{1}$ École d'orthophonie et d'audiologie, Université de Montréal, Montreal, QC, Canada, ${ }^{2}$ Centre for Research on Brain Language and Music, Montreal, QC, Canada, ${ }^{3}$ School of Communication Sciences and Disorders, Mc Gill University, Montreal, QC, Canada, ${ }^{4}$ Département de Psychologie, Université de Montréal, Montreal, QC, Canada

OPEN ACCESS

Edited by:

Juhani Järvikivi,

University of Alberta, Canada

Reviewed by:

Jana Reifegerste,

Georgetown University, United States

Raymond Bertram

University of Turku, Finland

*Correspondence:

Phaedra Royle

phaedra.royle@umontreal.ca

Specialty section:

This article was submitted to

Language Sciences,

a section of the journal

Frontiers in Communication

Received: 18 April 2018

Accepted: 02 April 2019

Published: 14 May 2019

Citation:

Royle P, Steinhauer K, Dessureault É, Herbay AC and Brambati SM (2019)

Aging and Language: Maintenance of

Morphological Representations in

Older Adults. Front. Commun. 4:16.

doi: 10.3389/fcomm.2019.00016
Studies employing primed lexical decision tasks have revealed morphological facilitation effects in children and young adults. It is unknown if this effect is preserved or diminished in older adults. In fact, only few studies have investigated age-related changes in morphological processing and results are inconsistent across studies. To address this issue, we investigated inflection morphology compared to orthographic and semantic processing in young and older adults. Twenty-six adults aged 60-85 and 22 younger adults aged 19-28 participated. We probed verb recognition using a sandwich-masked primed lexical decision paradigm. We investigated lexical decision using different prime presentation times (PPTs) (33, 66, and $150 \mathrm{~ms})$, and prime types with priming conditions involving orthographic (e.g., cassis-CASSE 'blackcurrant-break'), regular inflection morphological (cassait-CASSE 'broke-break'), and semantic primes (brise-CASSE 'break-break') and their controls, while measuring response accuracy and reaction times. Response accuracy analyses revealed that older participants performed at ceiling on the lexical decision task, and that accuracy levels were higher compared to young adults. Reaction-time data revealed effects of age group, priming condition, and an interaction of age group and morphological priming, but no PPT effects. Both young and older adults presented a significant facilitation effect (reduced reaction times) in the orthographic and morphological priming conditions. No semantic effects were observed in either group. Younger adults also showed a significantly stronger morphological priming effect, while older adults showed no difference between orthographic and morphological priming when comparing priming magnitudes. These findings suggest (1) that regular inflectional morphological processing benefits lexical access in younger French adults, confirming studies in other languages, and (2) that this advantage is reduced at older ages.

Keywords: aging, inflection morphology, masked priming, lexical decision, lexical semantics, orthographic processing, French

\section{INTRODUCTION}

This article addresses two objectives. Firstly, it aims to investigate the role of inflectional morphological representation in the French mental lexicon. Secondly, it aims to determine the effect of age on these morphological representations. Age has an impact on some aspects of language processing, in particular lexical access. This is anecdotally observed in everyday life. Older 
adults often manifest and report word-finding difficulties in spontaneous speech. These difficulties are confirmed by studies investigating characteristics of older adults' speech (Shewan and Henderson, 1988; Kemper et al., 2001; Kavé and Goral, 2017). This profile raises the question of whether lexical access difficulties are caused by word-representation degradation in the mental lexicon. While it is generally assumed that semantic aspects of word representations are preserved in older adults, little is known of age effects on morphology. This is a crucial issue for a better understanding of the nature of language difficulties encountered by normally-aging older adults in everyday life. To address this question, we deployed a masked primed lexicaldecision (LD) paradigm to investigate the relative impact of orthography, semantics, and morphology on word recognition in healthy French-speaking young and older adults.

In linguistics, morphology refers to the internal structure of complex words (e.g., in-divis-ible). Most words that we encounter are morphologically complex, i.e., they consist of at least two morphemes (e.g., indivisible, contains in-, divis- and ible). Morphemes can be described as minimal language units that possess a relatively consistent phonological or orthographic form and carry a part of the word's semantic or syntactic information. Many psycholinguists assume that morphemes and their meaning, rather than complex words, are stored in the mental lexicon, our long-term memory for words, and processed online. Thus, in order to understand a morphologically complex word, a listener's mind/brain has to decompose it into its morphemes and look up their corresponding information in the mental lexicon. Furthermore, morphemes can be recombined with other morphemes to create new words (Aronoff and Fudemann, 2011). From this perspective, morphological structure is an independent level of linguistic representation that needs to be processed online during language production and comprehension (see Amenta and Crepaldi, 2012, for a review). Some propose that morphological processing is obligatory and irrepressible (Stockall and Marantz, 2006). However, other researchers consider that words are processed as chunks, or whole words (e.g., indivisible), and that linking between the orthographic or phonological pattern of a word and its meaning does not require morphological representations or processing (Bates and Goodman, 1997; Seidenberg and Gonnerman, 2000; Devlin et al., 2004). According to this eliminativist stance, morphology is epiphenomenal to phonology/orthography or semantics and has no independent role to play in lexical representation and processing. Other more recent models assume that it is not necessary to postulate morphological, phonological or even semantic relations between words (see e.g., Baayen et al., 2011), and modeling morphological effects is processed via a symbolic layer of orthographic nodes and a symbolic layer of meanings, while using cue-based learning to predict outcomes and to learn (Milin et al., 2017). Note that there are hybrid (often termed dual-route) models where lexical processing can be both whole-word or morphological (e.g., high-frequency words may develop whole-word representations; Alegre and Gordon, 1999), but these frameworks are largely compatible with morphological models, as they also allow for morphemic representation (see e.g., Frauenfelder and Schreuder, 1992). In sum, the status of morphology is controversial across current theories of word recognition and production.

Why is morphology important? There is accumulating evidence that morphology impacts language acquisition and processing. Morphological awareness is important in learning language and writing development (Bertram et al., 2001; Pacton and Deacon, 2008; Quémart et al., 2011; Rvachew et al., 2017; Marquis and Royle, 2019). Given its role in language acquisition, we can wonder whether this ability is maintained during aging. Aging adults show heterogeneous patterns of cognitive abilities with some decline but also strengths relative to younger adults (see below and Ansaldo et al., 2013). Because morphology is implicated in lexical access, which can deteriorate with age, it is conceivable that morphological processing may also deteriorate with age. However, with respect to aging, the data on the impact of morphology in word reading remains rare and inconclusive. We review some studies focusing on morphological processing and aging below, but note that they are few and far between. First we discuss a classic research paradigm deployed for the study of morphology: primed lexical decision. This approach has the added value of allowing us to distinguish between different accounts of morphological processing, i.e., classical morphological representation vs. eliminativist approaches.

\section{Priming Studies}

Priming paradigms in conjunction with word processing tasks, such as lexical decision or go-no-go naming, are powerful tools to study the organization of the mental lexicon. Priming refers to a facilitation effect (or inhibition, when the effect is negative) in target stimulus processing, induced by the prior presentation of a related item (the prime). Participants' reaction times (RTs) and response accuracies (RAs) can be modulated by prime-target relationships. Target recognition facilitation in the form of decreased reaction times (RTs) have been reported for semantically related prime-target word pairs (such as doctornurse, Neely et al., 1989). Facilitation effects have also been reported when prime-target word pairs are orthographically or phonologically related (e.g., HELP-helm, Bijeljac-Babic et al., 1997). These findings have been interpreted as suggesting that the mental lexicon's organization is based on orthographic or phonological as well as semantic properties of words.

Priming studies have investigated whether morphological structure is an essential level of linguistic representation within the mental lexicon. Morphological priming has been investigated using different prime types, such as pseudo-derivational (e.g., corner-corn, where the pseudo-stem corn, is not part of corner's morphological structure), derivational (e.g., trucker-truck), or inflectional priming (e.g., vowed-vow). The majority of studies have focused on derivational priming (see e.g., Rastle and Davis, 2008; see Amenta and Crepaldi, 2012, for a review). However, we were interested in testing whether inflectional morphological processes have potential to facilitate lexical processing. Raveh and Rueckl (2000) shows that inflected and derived primes induce similar priming effects on stem recognition at $50 \mathrm{~ms}$ stimulus-onset asynchrony (SOA, the total amount of time between prime and target presentation, in this case a prime presentation time (PPT) of $40 \mathrm{~ms}$ plus $10 \mathrm{~ms}$ backward mask), 
while inflected words induced more priming than derivation at longer SOAs (150 and $250 \mathrm{~ms}$ ). Furthermore, inflectional morphological priming has the advantage of encoding regular semantic relationships, allowing for the study of highly constrained morphological effects (Royle et al., 2012), contrary to derivational morphological processes, which have variable semantic transparency, that is they can be opaque (e.g., archarcher), but can also change lexical category (e.g., to sailsailor). A study by Feldman and Prostko (2002) compared different types of priming on verb recognition in English. More specifically, they compared unmasked orthographically (and phonologically) related priming (e.g., vowel-vow) to semantic (e.g., promise-vow) and inflectional morphological priming (e.g., vowed-vow), in a number of different tasks and with different PPTs, ranging from barely perceptible primes $(33 \mathrm{~ms})$ to reliably perceptible $(116 \mathrm{~ms})$ and longer $(300 \mathrm{~ms})$. This type of manipulation allows one to investigate the time-course of different priming mechanisms and their respective decay during word processing. Overall, their data indicate that morphological priming is always facilitating (resulting in shorter RTs), while semantic and orthographic priming can be facilitating or not (or even inhibitory) depending on PPT and task. For instance, semantically oriented tasks, such as lexical decision and go-no-go naming, promote semantic priming effects, while orthographic effects are reduced or even inhibitory when the prime becomes perceptible. However, Feldman and Prostko interpret their data as being "[...] more compatible with a dynamic account where morphological effects emerge from conjoint influences of orthographic and semantic similarity that stabilize over time." (p. 25, our italics), that is, they promote an eliminitavist approach where so-called morphological effects are in fact the result of combined orthographic and semantic facilitation. If this is the case, morphological priming effects are expected to vary as a function of the orthographic (or phonological) and semantic overlap between the prime and target. Recall however, that Feldman and Prostko (2002) find orthographic facilitation during their priming task only at $66 \mathrm{~ms}$, and semantic priming only at long PPTs (116 and $300 \mathrm{~ms}$ ), while morphological facilitation was significant across all PPTs, suggesting that morphological priming cannot be explained by a combination of these two effects, which in turn makes an eliminativist interpretation for morphological priming hard to maintain. An important aspect of PPT manipulations is that they are assumed to constrain or highlight different cognitive processes underlying lexical access. Effects arising at shorter PPTs or processing times (SOAs) are assumed to reflect automatic and less strategic processing, while those emerging after longer PPTs are assumed to reflect less automatic, and more strategic, or even post-lexical processing (see e.g., McKoon and Ratcliff, 1995; Steinhauer et al., 2017). Primes are typically perceived at about $60 \mathrm{~ms}$ PPT, without participants being able to identify what they are (Forster, 1998). However some participants can be more or less attuned to primes at these PPTs, depending on their inherent processing abilities or whether masking is used (Brown and Hagoort, 1993; e.g., Deacon et al., 2000). As presented above, some priming effects (e.g., orthography/phonology and morphology) systematically arise at shorter PPTs, while others (e.g., semantics) typically arise at longer PPTs. Manipulating PPTs thus allows us to test whether semantic, morphological and orthographic priming are "on line" at different points in processing and whether these effects are maintained in aging.

The facilitation effect of morphologically-related primes on target-word RTs has been more recently demonstrated in French-speaking participants. Quémart et al. (2011) compared young adult and child participant groups with forward-masked priming using different PPTs $\left(60,250\right.$ and $\left.800 \mathrm{~ms}^{1}\right)$ and four types of prime: pseudo-morphemic (such as baguettebague 'baguette-ring,' where there is no shared stem between the prime and the target but a pseudo-parse is possible bague + ette 'ring + diminutive'), morphologically derived forms (tablette-table, 'shelf-table'), orthographic (abricot-abri 'apricot-shelter') and semantic (tulipe-fleur, 'tulip-flower'). Their results are globally similar to those of Feldman and Prostko (2002) in that morphological priming effects were constant across PPTs and groups, while other effects (orthographic and semantic) varied by group and PPT. At $60 \mathrm{~ms}$ PPTs, orthographic and semantic effects were non-significant in children and adults, while pseudo-morphological forms showed similar priming to true morphological priming: responses were faster by $25 \mathrm{~ms}$ on average. In adults, when the PPT was increased to $250 \mathrm{~ms}$ the data converged on previous results, with significant morphological priming (56 ms), no semantic, or orthographic priming, and a disappearance of pseudo-derived priming effects. The authors interpreted this as signaling an early morpho-orthographic processing stage, followed by a later lexical-semantic stage, linked to longer PPTs and prime perceptibility (Meunier and Longtin, 2007; Quémart et al., 2011). Similarly, an eventrelated potential (ERP) study by Royle et al. (2012) tested inflectional morphology, semantic, and orthographic priming effects on inflected verb recognition in French-speaking young adults, using sandwich-masked priming and a PPT of $50 \mathrm{~ms}$. No significant RT differences were found for orthographic or semantic priming relative to unrelated pairs, while morphological priming reliably sped up target recognition by $29 \mathrm{~ms}$ on average. Additional ERP data from this study support autonomous morphological processing, as the authors found strong and long-lasting ERP modulation for morphological priming, weak and short-lasting modulation for orthographic priming, and no effects for semantic priming.

Globally, these results point to the interpretation that French speakers with ages varying from beginning readers to young adults rely on morphemic information when processing words, and that this process is distinct from orthography and semantics. Importantly, masked priming is known to block semantic effects, therefore allowing us to test whether morphological effects are parasitic on semantic ones, as suggested by eliminativists. The ERP study did not manipulate PPT, and it could be argued that at longer PPTs semantic processes could play a role in morphological priming. The present study therefore addresses this issue using the same paradigm and virtually the same

\footnotetext{
${ }^{1}$ We report results for PPTs used with adults -60 and $250 \mathrm{~ms}-$ but additional interesting results are reported for children at $800 \mathrm{~ms}$, we refer the interested reader to this article for more details.
} 
materials as Royle et al. (2012) in young and older adults, while manipulating PPT as in Feldman and Prostko (2002).

\section{Aging and Cognition}

A motivation for our age group comparison is that it is unresolved whether morphological representation and processing changes or remains stable at later stages of the lifespan. Aging is a multidimensional process that produces changes, to various extents, in different brain and cognitive functions. Older adults, compared to younger ones, show structural changes in terms of gray and white matter volume reduction (Raz et al., 1997, 2004; Good et al., 2001; Fjell et al., 2013; Lindemer et al., 2017) or reduced brain connectivity (Montembeault et al., 2012). These age-related changes are often accompanied by performance decline in additional cognitive processes such as executive function (i.e., attentional control, inhibition, working memory, and task monitoring), and episodic memory (Gordon and Kurczek, 2014). Word processing is thought to remain relatively stable in older adults. However, studies comparing younger and older adults have provided conflicting results depending on the nature of the task employed. On the one hand, it has been shown that older adults exhibit lower performance than younger ones in lexical retrieval tasks using explicit and effortful paradigms such as picture naming and word naming from definitions (Bowles and Poon, 1985; Verhaegen and Poncelet, 2013). However, it must be noted that these tasks require word retrieval or word planning. Both these processes rely on executive function abilities (such as attention) (Murray, 2000; Roelofs and Piai, 2011), which are sensitive to aging (Sylvain-Roy et al., 2015). On the other hand, when executive function effects are minimized using tasks that do not require explicit lexical access, such as priming paradigms with word stimuli, studies have often reported comparable performance in older, and younger participants (e.g., Lustig and Buckner, 2004). Together, these findings seem to suggest that (1) word representations are preserved in older populations and, (2) priming tasks could clarify the role of morphological representation in lexical access while minimizing the impact of other cognitive processes. For example, previous priming studies comparing older and younger adults have shown that semantic and orthographic priming are preserved in older adults (Madden et al., 1993).

Although aging adults show lexical access difficulties (e.g., tip-of-the-tongue states), few differences are observed between older and younger adults in language processing tasks, but inflectional morphology is surprisingly neglected. Most studies have investigated semantic priming effects (see Giffard et al., 2003 for a review) and very few (see Reifegerste et al., 2018) have investigated inflectional morphology priming. We present some studies of lexical access involving semantic, orthographic, and compound morpheme priming before presenting studies of inflection priming proper. Older participants show equal or stronger semantic priming than younger ones (see Burke, 1997, for a review), and evidence for deterioration in confrontation naming varies depending on studies, can be subtle, and may appear only in the seventh or eighth decade of life (Feyereisen, 1997; Connor et al., 2004; Zec et al., 2005; Obler et al.,
2010) thus supporting robust lexical representation despite declining cognitive abilities. However, some have argued that older speakers have a higher dependence on whole word or semantic processing with aging (Patterson et al., 2007; Grieder et al., 2012; Provost et al., 2016; Chapleau et al., 2017). (Grieder et al., 2012) show similar strengths in aged (60-78 years) and younger Swedish-speaking adults, using semantic priming tasks in conjunction with ERP methods. Some studies show phonological difficulties in word production (MacKay and James, 2004) and priming, suggesting this might be a domain of weakness (James and Burke, 2000). Moscoso Del Prado Martín (2017) observes a decrease in morphological diversity in spontaneous speech with aging. No aging effects are found for the magnitude of morphological priming in Spanish compounds (e.g., pasa-PASATIEMPO 'pass-pastime') (Duñabeitia et al., 2009). Thus, morphological processing has not yet been shown to be a clear domain of weakness. Note that even though the reviewed studies mostly focus on lexical-semantic or phonological-orthographic processing abilities, these are relevant to models of morphological processing, especially those that argue that morphological processing is an epiphenomenon of semantic and orthographic processing.

\section{Inflectional Morphology and Aging}

A small number of recent studies using priming paradigms have focused more specifically on inflection processing in aging German speakers. These studies generally assume that morphological processing is available to all speakers, and investigate whether different types of inflection (namely regular vs. irregular, the first being more likely to be morphologically parsed) are processed in similar or different ways. Using crossmodal (auditory-visual) unmasked priming with no interval between the prime and target, Reifegerste and Clahsen (2017) establish that German-speaking adults (aged 50-83, $N=32$, 23 women) show strong inflectional morphologial priming effects for regular inflected adjectives (e.g., blaue-blaues 'blue'), but weaker priming for irregular verbs (e.g., werfenwirft, 'to-throw-throws'), as compared to identity priming (e.g., wirft-wirft). In a second study Clahsen and Reifegerste (2017) compare priming for regular and irregular verbs with similar participant groups and methods. They show less priming for irregular (e.g., geschlafent-schlafe 'slept-sleeps') vs. regular verbs (e.g., getanzt-tanze 'danced-dances') and, contrary to younger adults, older German speakers do not show priming for irregular verbs. Finally, Reifegerste et al. (2018) observe similar magnitudes of priming, in older and younger German speakers, for forward-masked derivation priming (e.g., Warnung-warnen 'warning-to-warn') and regular inflection priming (vs. gewarnt-warnen 'warned-to-warn'). No reliable orthographic (e.g., Kasse-Kasten 'cash register-box') or semantic priming (e.g., Tisch-Stuhl 'table-chair') was found. This body of work suggests that inflection morphological processing is stable in older adults but that some aspects of irregular inflection processing, possibly linked to the long-term memory storage of lexical representations (Reifegerste et al., 2018) or orthographic/phonological processing, can be less efficient. A few issues remain. No direct comparison to younger adults is made 
in Reifegerste and Clahsen (2017), and they compare regular adjectives to irregular verbs. The grammatical information on verb tense/person/number inflection vs. case/number marking on adjectives is a potential confound making their conditions less than ideal for direct comparisons. The second study (Clahsen and Reifegerste, 2017) contains no semantic, nor orthographic, control conditions to test for meaning or form overlap between prime and target, and, astonishingly, repetition priming did not show any advantage over unrelated priming ${ }^{2}$. Reifegerste et al. (2018) do have orthographic and semantic control conditions, but use different target words (see examples above), which is not ideal.

Thus, the study of inflectional morphological priming in young and older adults appears to provide critical information allowing us to better understand the effects of aging on word morphological representation. Our study will improve the state of knowledge on inflection morphological processing in aging as we will tease apart aging effects on semantic, orthographic, and morphological representations on lexical access. Based on results of previous studies, we hypothesized that young adults would show robust and equivalent morphological priming effects (i.e., faster RTs) across different PPTs, while orthographic effects would be absent or inhibitory in long PPTs (66 and $150 \mathrm{~ms}$ ) but present when the prime is not perceptible $(33 \mathrm{~ms}$ PPT). If at all, semantic priming was expected only when the prime was robustly perceptible $(150 \mathrm{~ms}$ PPT). We expected older adults to show globally similar patterns as younger ones since, as far as the literature shows, no impairment specific to regular inflectional morphological processing has been supported, excluding MacKay and James (2004) and Moscoso Del Prado Martín (2017).

\section{METHODS}

\section{Participants}

Twenty-four young adults (aged 19-28, 12 women, two lefthanders one for each sex) and 25 older adults (aged 61-80, 12 women, one male left-hander) participated in the study. Eleven older adults were between ages 61 and 70, and 14 between 71 and 80 . No participant had a history of language or reading impairment, neurological damage or impairment. They all had normal or corrected-to-normal vision. All were native French speakers and lived in predominantly French-speaking environments. In order to exclude the presence of mild cognitive impairment, all participants were screened using the Minimental (French adaptation of the MMS, Folstein et al., 1975; Derouesné et al., 1999). Older participants were additionally evaluated using the Montreal Cognitive Assessment (MoCA, Nasreddine et al., 2005). An X-test was also used to evaluate basic motor response times. This was used to obtain a measure of simple visual reaction times. In this test, participants were presented with a white fixation dot in the center of a black screen of the laptop, followed after variable time intervals by

\footnotetext{
${ }^{2}$ They report confusion in some participants as to the task instructions, and specifically when confronted with repetition priming. These participants should probably have been discarded from the study.
}

a white cross target stimulus. Participants were asked to press the space bar on the laptop keyboard as quickly as possible when the white cross appeared on the screen. Scores on the MMS did not vary according to participant group (Younger: $M=29.23, S D=0.75$; Older: $M=29.08, S D=0.86, t$-test assuming equal variance $=0.62 p=0.269)$. No differences were found on MMS scores between the older sub-groups (6170: $M=29.09, S D=0.70 ; 71-80, M=29.07, S D=0.99$, $t=0.5, p=0.48)$. MoCA scores in older adults were 28.21 on average $(S D=1.25)$. No difference was observed on the MoCA between participants aged $61-70(M=28, S D=1.18)$ and participants aged 71 to $80(M=28.38, S D=1.33$, $t=-0.25, p=0.40)$. Participants did not differ on education levels (Younger: $M=15.64, S D=1.71$, range 14-22; Older: $M=16.12, S D=3.18$, range $13-25, t$-test assuming unequal variance $=-0.64 p=0.262$ ). However, both groups differed on their mean motor responses to the X-test (Younger: $291.65 \mathrm{~ms}$, $S D=38.56$; Older: $330.67, S D=42.67, t$-test assuming equal variance $=-3.27 p=0.002$, see Supplementary Figure 1). Participants received 40\$CAD for their participation and signed informed consent to participate. The project was approved by the ethics committees of the Université de Montréal Faculty of Medicine, and the Center de recherche de l'Institut universitaire de gériatrie de Montréal (CRIUGM).

\section{Procedure}

After reading and signing informed consent, younger participants were comfortably seated in a quiet room at the Université de Montréal, and older participants at the CRIUGM, in front of a HP D8907 p720 computer screen $45 \mathrm{~cm}$ from their face. They were asked to judge whether letter strings presented on the screen were real words of French or not. They were asked to respond as rapidly and accurately as possible. They were advised that the string would be preceded by a series of hash marks. They were not explicitly told about the prime, just that they had to respond after the hash marks. The participants' dominant hand was used to respond YES, and the non-dominant hand for NO, using S and L keys. Stimuli were presented with Eprime 2.0 (Zuccolotto et al., 2012) and response accuracies (RAs) as well as reaction times (RTs) were recorded with this program. Each trial started with the presentation of a fixation point ( + ), a forward mask (\#\#\#\#\#\#\#) for $500 \mathrm{~ms}$, followed by a prime that was replaced after 33, 66 or $150 \mathrm{~ms}$, by a backward mask for $20 \mathrm{~ms}$, and then by the target on which participants made a lexical decision. The target disappeared when a decision was made, or else after $2,500 \mathrm{~ms}$. A white screen followed for $1 \mathrm{~s}$, and a new trial started. Two pauses were programmed within each list. Participants controlled pause length. No feedback was given on responses, and total testing time lasted between 45 and 55 minutes.

\section{Stimuli}

Here we present a brief description of priming conditions, timing and list development, see Royle et al. (2012) for details on stimulus properties. A master list using 42 regular target verbs and their six priming conditions was developed. The morphological, orthographic and semantic conditions 
each had their control prime matched for frequency and length. The semantic priming condition involved synonyms or troponyms (e.g., brise-CASSE, 'break-break') to mirror the semantic relationship between inflected verb forms as closely as possible. The orthographic condition involved a prime that was orthographically similar to the target without shared morphological structure or semantics (e.g., cassisCASSE, 'blackcurrant-break'). In the morphological condition, the third person singular imperfect form of the verb was used as a prime (cassait_CASSE, 'broke-break'). Orthographic and morphological pairs were individually matched on the amount of orthographic, phonological and syllabic overlap they shared with the target. All primes were matched on form frequency and length (letters, phonemes and syllables), and in the case of morphological controls, internal word structure (e.g., disaitCASSE, 'said-break' matched with cassait-CASSE). We used the same target in all conditions in order to be able to directly compare different priming effects on target recognition. The prime and target were always presented in different fonts to avoid retinal imprints and visual overlap on the presented items. Forward and backward masks were used to reduce conscious priming and erase retinal imprints. The three PPTs used $(33,66$, and $150 \mathrm{~ms}$ ) were repeated across conditions (i.e., 42 items in 6 priming conditions and 3 PPT times). Based on this master list, nine lists were created with pseudo randomized orders, making sure that each target was not seen more than twice in each list (always in a given condition, with a specific PPT and its control priming condition). Within a list, 84 prime-target pairs were distributed into four blocks such that the same target was presented in maximally distant blocks of items (i.e., blocks $1-3$ or 2-4). In younger adults, 42 real word filler pairs, 126 non-word target filler items and 8 practice items were added to each list. In total, each list contained 252 items and took no more than 15 minutes to complete. The stimuli used in older adults were the same as for younger ones except for 9 items that were excluded from the analyses in younger adults (see Statistical analyses below). Thus, older adults were presented with 33 critical items in each of the 6 experimental conditions, at three PPTs, randomized across nine lists, for a total of 234 items per list, including fillers. All participants were tested by the third author.

\section{Testing Sessions}

Participants came to three or four different 50-minutes sessions in the lab over a 3- or 4-week period: young adults were presented with three lexical decision stimulus lists per visit, while older adults were presented with two on the first three visits and three on the last one. These were presented in pseudo-random orders to each participant in order to avoid biases linked to sequence effects. Thus, all participants saw all nine lists. During the first meeting, all participants filled in a demographic questionnaire with specifics on their communication habits and medical antecedents. This was followed by their first experimental list, a visual acuity test, the MoCA cognitive screening test and the following list(s). In the second session, between the two first experimental lists, they were given the Mini-mental cognitive evaluation. During the third session, participants were tested on the $\mathrm{X}$-test in addition to their lists. An average response time score was calculated for each participant. Finally, on the fourth meeting, all older participants completed three lexical decision stimulus lists.

\section{Statistical Analyses}

Following preliminary analyses of the young adult data, two participants were excluded because they had more than $20 \%$ error rates. Each item's recognition score was calculated and those with a level below $75 \%$ were eliminated from the analysis (the nine items were: bride 'put a bridle on,' chipe 'steal,' fane 'wilt,' farde 'put on makeup, ferre 'shoe a horse/nail a horseshoe, fuse 'burst forth,' hume 'inhale/smell', hale 'haul,' and larde 'pierce/hurt'). Thus, 22 young participants (aged 19-28) and 33 targets were retained. Older adults were tested only on this subset in items and analyses were run on this subset in both groups. A response contingent RT analysis was performed on critical items $(9.74 \%$ of the data were excluded). Extreme responses beyond $1.5 \mathrm{~s}$, were also eliminated (this accounted for $0.57 \%$ of the data).

Target accuracy and reaction time data were subjected to linear mixed effect models using the lme4 package 1.1.12 in $\mathrm{R}$ (Bates et al., 2015). Fixed effects included in models were PRIMETYPE (morphological, orthographic semantic,-minus their control conditions in RT data, see below-dummy coded with morphological prime as reference level, as it is at the core of the present study), prime presentation time (zPPT, as a standardized version of the continuous variable, PPT, using the rescale function from the arm R package, Gelman and Su, 2018), and zAGEGROUP (a standardized version of the factorial binary variable AGEGROUP). ZPPT and ZAGEGROUP were normalized given their two very different scales. This procedure centered these two variables on 0 , allowing us to establish a meaningful intercept that is the mean priming effect (at the reference level of PRIMETYPE) independent of age group and PPT. Randomeffect factors Subject and ITEM, as well as random slopes for TRIAL (chronological trial order within a list, continuous, $z$ scored: zTRIAL), testing DAY (continuous, centered: CDAY), list presentation ORDER (continuous, centered: CORDER) and mean reaction time on the X-test (RTX) were used in target accuracy analyses. Only random intercepts with an intraclass correlation coefficient (ICC) of more than 0.05 , calculated with the sjstats package (Lüdecke, 2017), were retained. In RT analyses, we

TABLE 1 | Glmer model for response accuracy: fixed effects for the factors Group and PRIMETYPE.

\begin{tabular}{lrrrr}
\hline & Estimate & Std. error & $\boldsymbol{t}$ & $\operatorname{Pr}(>|\mathbf{t}|)$ \\
\hline Intercept & 2.5573 & 0.2312 & 11.061 & $<0.0001$ \\
Orthographic control & -0.0053 & 0.0899 & -0.059 & 0.95298 \\
Semantic control & -0.0236 & 0.0896 & -0.263 & 0.79246 \\
Morphological & 0.2695 & 0.0949 & 2.837 & 0.00455 \\
Orthographic & 0.3668 & 0.0971 & 3.779 & 0.00016 \\
Semantic & -0.0326 & 0.0894 & -0.364 & 0.71549 \\
Group (Older Adults) & 1.4869 & 0.3132 & 4.747 & $<0.0001$ \\
\hline
\end{tabular}

Nb. of observations $=27834$, log likelihood -5236.3 . The reference level for group is younger adults and for prime is morphological control. 
TABLE 2 | Response accuracy and response times (RTs) in means (and standard deviations) for all priming conditions in each participant Group (younger vs. older).

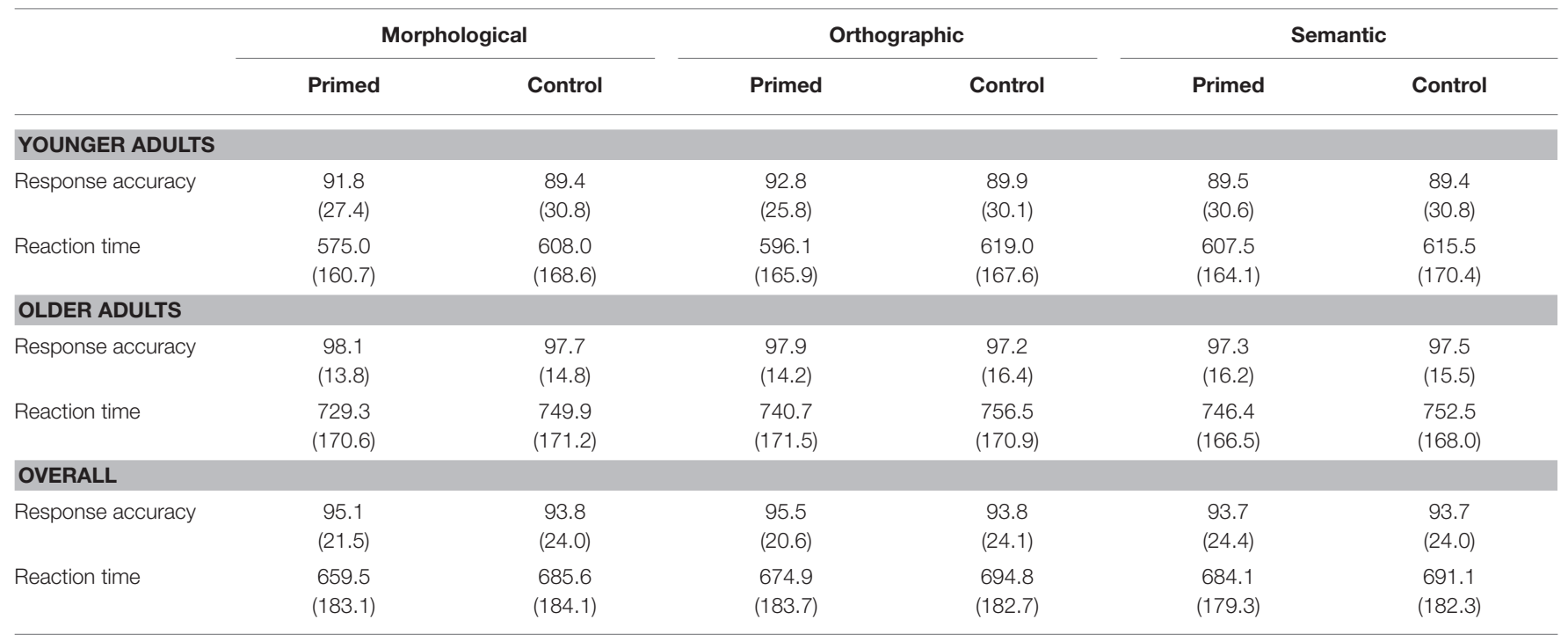

calculated differences between control and primed conditions. This precluded the use of TRIAL as a random-effect factor for these analyses. We started with a maximal random-effects structure, simplifying the model in cases of convergence failure, and modeled factors as interactions until we reached the best fit, determined by comparing two minimally different models using the anova() function to perform the likelihood ratio test, and assess the significance of effects of the fixed factors as main effects as well as their interactions. This was assessed by comparing a model containing the interaction in question, either to a model containing only the relevant lower-level interactions or to a model containing only the relevant main effects. In order to make the selected models easier to interpret, we used the ANOVA wrapper (Type III Wald chi-square test) in the car package (Fox and Weisberg, 2011). When needed, post-hoc pairwise comparisons were performed using the emmeans package 1.3.0 in $\mathrm{R}$ (Lenth, 2018). A first analysis involved response accuracy (RA) and a second one modeled response-contingent reaction times (RTs).

\section{RESULTS}

\section{Response Accuracy}

We tested for non-linear effects of covariates and for a contribution of by-participant random slopes for ZTRIAL, CDAY, RTX, and CORDER. We established these did not significantly improve the model, nor did the random factor ITEM (ICC $=0.0417)$. SubJECT was included as a random factor $(\mathrm{ICC}=0.0846)$. The maximal structure containing all fixed effects (Group, PrimeType, CPPT, CAGE) and the random factor SUBJECT failed to converge. The best model for RAs included the fixed effects Group and PRIMETyPE but no interaction of these (AIC: 10488.5, see Tables 1,2). PPT never reached significance as a simple effect nor in interaction with other simple effects. Post-hoc contrasts using lsmeans revealed significant differences between orthographic control and orthographic priming conditions, $t=-3.83, p=0.0017$, morphological, and semantic priming conditions, $t=3.197$, $p=0.0174$, as well as orthographic and semantic priming conditions, $t=4.135, p=0.0005$. In other words, we found small but significant priming effects for orthography and morphology (i.e., higher accuracy for primed compared to control items), whereas no such effect was observed for the semantic condition. GROUP effects reflected the fact that older adults showed higher levels of correct responses $(97.64 \%, S D=0.15)$ than younger adults $(90.46 \%, S D=0.29)$, who in turn displayed more withingroup variability (as reflected by SDs). In essence, scores are globally high in all groups across all conditions, especially in older adults, with the lowest scores found in control and semantic priming conditions.

\section{Reaction Time Data}

Older participants were on average $102 \mathrm{~ms}$ slower than young adults, which is some $62 \mathrm{~ms}$ more than the motor-related differences found in the X-test (see Table 2 for RTs by condition). In order to quantify priming effects, we subtracted each primedcondition reaction time from their control-condition reaction time for each item, at each PPT, within each participant. These data, summarized in Table 3, were then entered into mixed models. We tested for non-linear effects of covariates and for a contribution of by-participant random slopes for CDAY and CORDER (TRIAL could not be measured due to the subtraction process, while RTX effects did not significantly contribute to the model). Surprisingly, adding the factor zPPT to the model did not improve its likelihood either, but this factor was maintained in order to illustrate a lack of effect, as it was part of the experimental design. Models were fit using the maximal random effect structure justified by the design that would converge on the data (Barr et al., 2013). The maximal structure contained all fixed effects (zAgeGroup, PrimeTyPe, zPPT), their interactions, bySUBJECT and by-ITEM random intercepts as well as by-ITEM random slopes for the interaction PRIMETYPE*ZPPT (AIC: 
TABLE 3 | Average priming effects for Groups, Prime type and PPT (non-weighted means).

\begin{tabular}{llcccc}
\hline \multirow{2}{*}{ Group } & Prime type & \multicolumn{3}{c}{ PPT } \\
\cline { 3 - 4 } Young & Morphological & 37.06 & 39.36 & 27.72 & \multirow{2}{*}{ Average } \\
\cline { 3 - 4 } & Orthographic & 25.38 & 19.63 & 26.05 & 23.69 \\
\multirow{3}{*}{ Older } & Semantic & 15.32 & 12.74 & 1.28 & 9.78 \\
& Morphological & 16.08 & 19.12 & 22.82 & 19.34 \\
& Orthographic & 17.33 & 22.05 & 11.50 & 16.96 \\
& Semantic & 11.20 & 10.67 & -0.16 & 7.24 \\
& Morphological & 26.57 & 29.24 & 25.27 & 27.03 \\
& Orthographic & 21.35 & 20.84 & 18.77 & 20.32 \\
& Semantic & 13.26 & 11.71 & 0.56 & 8.51 \\
\hline
\end{tabular}

165010.8). This model included the fixed effects PRIMETyPE, ZAGEGroup, ZPPT and the interaction between PRIMETYPE and ZAGEGROUP, by-SUBJECT and by-ITEM random intercepts as well as by-ITEM random slopes for PRIMETyPE and ZPPT effects (AIC $=165034.8)$. This model does not significantly differ from the maximal model $\left(\chi_{(1)}^{2}=24.02, p=0.09\right)$. Results of the corresponding analysis are presented in Table 4, and Figure 1 illustrates the underlying data by PRIMETYPE and ZAGEGROUP (but collapsed across PPT levels, as PPT never contributed significantly to the models).

The data can be summarized by three main observations (Figure 1). First, all priming effects were numerically larger in the group of young adults. Secondly, in both age groups, morphological priming showed the strongest RT effect, followed by orthographic priming, and finally by a very small and non-significant semantic priming effect. Thirdly, the group differences were most prominent in the morphological condition. Thus, whereas young adults' response times seemed to profit considerably more from morphological priming $(35 \mathrm{~ms})$ than from orthographic priming $(24 \mathrm{~ms})$, in older participants both types of priming reduced response times to almost the same extent (19 and $17 \mathrm{~ms}$, respectively). These observations are largely confirmed by statistical analyses, which however also pointed to some ambiguities.

With morphological priming being the reference level for PRIMETYPE, and age groups being represented by a normalized and centered variable (zAgEGroup), all effects in Table 4 must be interpreted relative to morphological priming across both age groups. The overall morphological priming effect (intercept of $26 \mathrm{~ms}$ ) was highly significant and did not statistically differ from the orthographic priming effect $(21 \mathrm{~ms})$, while a significant difference was found between morphological and semantic priming $(8 \mathrm{~ms})$, suggesting that the latter was not significantly different from zero. ZPPT did not contribute to any significant effects. Crucially, morphological priming was significantly modulated by ZAGEGROUP $(p<0.006)$, i.e., the priming effect of $35 \mathrm{~ms}$ in young adults was significantly larger than the $24 \mathrm{~ms}$ effect in older adults. On the other hand, the difference between morphological and semantic priming was
TABLE 4 | Lmer model for priming effects with fixed effects of PRIMETYPE, ZAGEGroup, and zPPT as well as the interaction between PRIMETyPE and ZAGEGROUP.

\begin{tabular}{lcccc}
\hline & Estimate & Std. error & $\boldsymbol{t}$ & $\operatorname{Pr}(>|\mathbf{t}|)$ \\
\hline Intercept & 26.004 & 6.692 & 3.886 & $<0.001$ \\
Orthographic prime & -5.039 & 10.982 & -0.459 & 0.649 \\
Semantic prime & -17.944 & 6.117 & -2.933 & 0.006 \\
ZAGEGroup & -15.443 & 5.583 & -2.766 & 0.006 \\
zPPT & -5.138 & 3.902 & -1.317 & 0.197 \\
Orthographic prime:ZAGEGroup & 8.234 & 7.575 & 1.087 & 0.277 \\
Semantic prime:ZAGEGroup & 13.030 & 7.610 & 1.712 & 0.087 \\
\hline
\end{tabular}

As random effects, random intercepts for SUBJECT and ITEM are included, as well as by-ITEM random slopes for the effects of PRIMETYPE and ZPPT. The reference level for PRIMETYPE is morphological prime. Nb. of observations $=12,550$.

only marginally influenced by ZAGEGroup $(p<0.09$ ). Nonsignificant results for the difference between orthographic and morphological priming $(p=0.649)$ and for its modulation by age (i.e., Orthographic prime:zAGEGROUP; $p=0.277$ ) indicated that orthographic priming showed a similar pattern as morphological priming. Thus, based on this analysis alone, the RT data seem to suggest that (a) orthographic and morphological conditions both showed comparable (significant) priming effects in both groups (although more so in young participants), and that (b) they equally differed from the semantic condition that did not show any priming. However, these assumptions may be an oversimplification. An additional direct contrast between orthographic and semantic conditions revealed that these two conditions did not statistically differ from each other either ( $p=0.4219$ ). In fact, when running the same model as above, but with the semantic priming condition as the reference, the results suggest a distinct pattern, as shown in Table 5. Now, the orthographic priming condition seems to pattern with the semantic rather the morphological condition, i.e., neither the orthographic priming effect nor its interaction with ZAGEGROUP differ from the (non-significant) patterns of the semantic condition. The only significant effect in this version of the model is (again) the difference between semantic and morphological priming $(p=0.006)$, which moreover marginally interacted with age $(p=0.087)$. In other words, whereas a clear morphological priming effect could be reliably distinguished from a very weak (or absent) semantic priming effect irrespective of the model version, the status of the orthographic priming condition remained unclear as it did not significantly differ from either morphological priming (Table 4) or from semantic priming (Table 5). Intriguingly, the ambiguity regarding orthographic priming also extends to the important question of whether or not its magnitude differed between young and older participants. Table 4 suggests it is modulated by age-as with morphological priming - whereas Table 5 suggests it is not modulated by agesimilar to the semantic priming condition. Moreover, the finding that, in both models, the impact of age groups on the difference between semantic and morphological priming was only marginal $(p=0.087)$ results in a number of possible interpretations, depending on whether a marginally significant interaction is treated (a) as a non-significant result or rather (b) as a suggestive 


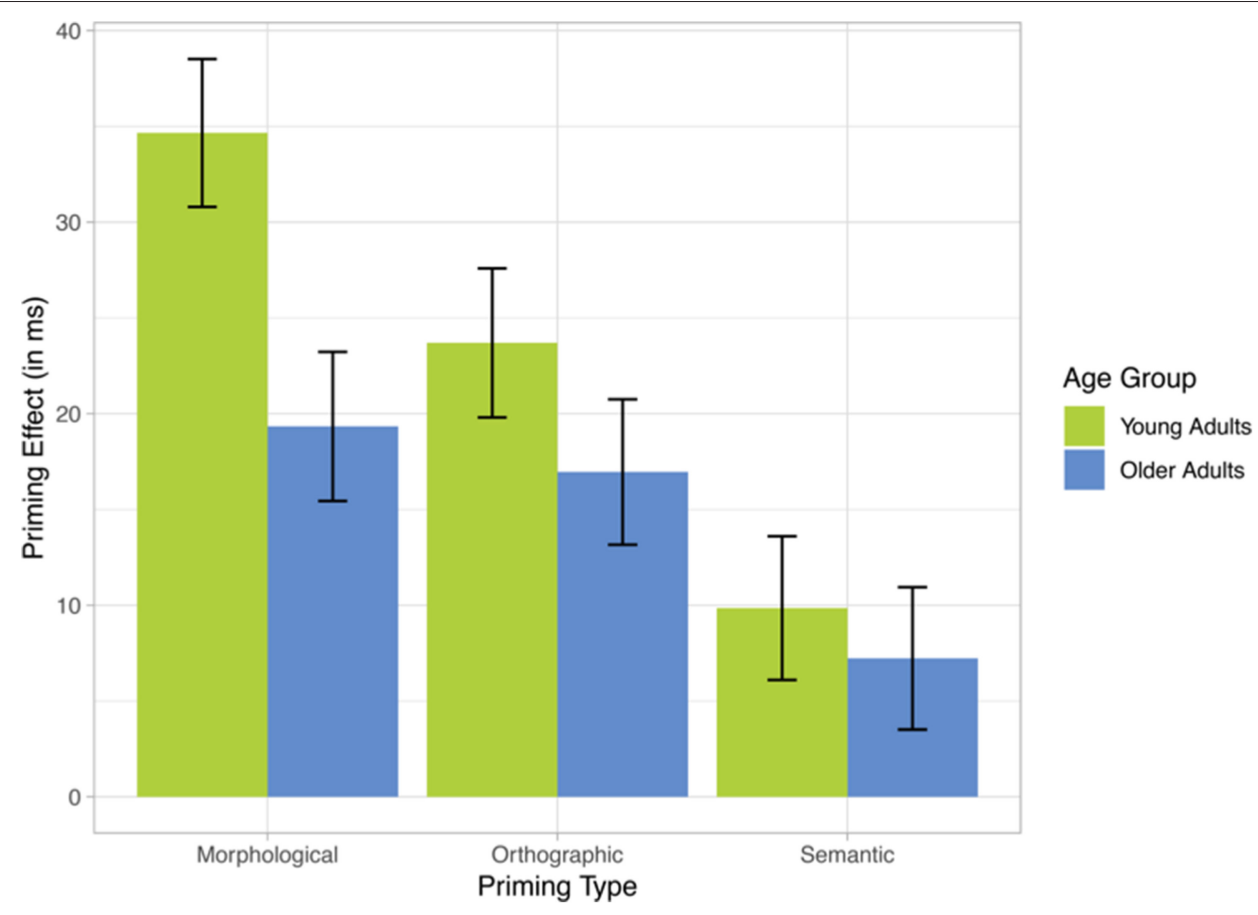

FIGURE 1 | mean primary effects (RTs in control minus primary condition), and standard errors, in morphological, orthographic, and semantic conditions, in younger and older French-speaking adults.

TABLE 5 | Lmer model for priming effects with fixed effects of PRIMETYPE, ZAGEGROUP and zPPT as well as the interaction between PRIMETyPE and ZAGEGROUP.

\begin{tabular}{lcccc}
\hline & Estimate & Std. error & $\boldsymbol{t}$ & $\operatorname{Pr}(>|\mathbf{t}|)$ \\
\hline Intercept & 8.060 & 6.025 & 1.338 & 0.190 \\
Morphological prime & 17.944 & 6.117 & 2.933 & 0.006 \\
Orthographic prime & 12.905 & 10.517 & 1.227 & 0.229 \\
ZAGEGroup & -2.412 & 5.612 & -0.430 & 0.667 \\
zPPT & -5.138 & 3.902 & -1.317 & 0.198 \\
Morphological & -13.030 & 7.610 & -1.712 & 0.087 \\
prime:ZAGEGRoup & & & & \\
Orthographic prime:ZAGEGroup & -4.797 & 7.597 & -0.631 & 0.5277
\end{tabular}

As random effects, random intercepts for SUBJECT and ITEM are included, as well as by-ITEM random slopes for the effects of PRIMETYPE and zPPT. The reference level for PRIMETYPE is semantic prime. Nb. of observations $=12,550$.

effect. In the former case (a), Table 4 with its highly significant zAGEGROUP effect for morphological priming and no further interactions involving age groups suggests (i) an age effect being present across the board in all three priming conditions; whereas Table 5 suggests (ii) that age effects were absent across the board. In the latter case (b), the pattern would suggest either (iii) that age influences were present only for morphological and orthographic conditions, but not for semantics (Table 4), or (iv) that age affected only the morphological priming condition (Table 5).

In our opinion, the inconsistencies described above point to a rather ambiguous pattern of results that call for additional analyses. To further clarify the actual pattern, we ran separate models within each priming condition-and found three different patterns.

\section{Separate Models for the Three Priming Conditions and for Morphological Priming vs. Morphological Control Conditions}

We developed models for each level of PRIMETYPE separately while again investigating whether zPPT and zAGEGROUP would affect these. As zPPT never led to any significant effects (all $p$ 's $>0.16$ ), we will not report these data separately.

A first model for morphological priming (Table 6) revealed both a highly significant priming effect $(t=3.858 ; p<0.001)$ and a strong main effect of zAGEGROUP $(t=-2.609 ; p=0.0124)$, confirming that morphological priming was significantly reduced in older participants. To better understand if the group of older participants showed any evidence of morphological priming, we followed up with analyses in each group. These post-hoc analyses demonstrated that morphological priming was very strong and extremely significant in young adults $(\beta=34.2 \mathrm{~ms}$; $p=2.2 \mathrm{e}-16$; based on 1,848 observations), whereas it was considerably weaker-though still highly significant-in older adults ( $\beta=19.2 \mathrm{~ms} ; p=7.158 \mathrm{e}-07$; based on 2,342 observations). Note that this result is exactly what we found when running models on original unsubtracted RT data for morphological vs. control priming. In that analysis the group differences were reflected by a significant morphological priming by age group interaction $(p=0.02)$. 
TABLE 6 | Lmer model for morphological priming with fixed effects of ZAGEGROUP and zPPT, as well as their interaction.

\begin{tabular}{lcccc}
\hline & Estimate & Std. error & $\boldsymbol{t}$ & $\operatorname{Pr}(>|\mathbf{t}|)$ \\
\hline Morph Intercept & 26.098 & 6.764 & 3.858 & $<0.001$ \\
Morph ZAGEGrouP & -15.568 & 5.968 & -2.609 & 0.012 \\
zPPT & -1.281 & 6.384 & -0.201 & 0.842 \\
ZAGEGroup:ZPPT & 15.078 & 10.891 & 1.384 & 0.166 \\
\hline
\end{tabular}

As random effects, random intercepts for SUBJECT and ITEM are included, as well as by-ITEM random slopes for the effect of ZPPT. Nb. of observations $=4,190$.

TABLE 7 | Lmer model for orthographic priming with fixed effects of ZAGEGROUP and zPPT, as well as their interaction.

\begin{tabular}{lcccc}
\hline & Estimate & Std. error & $\boldsymbol{t}$ & $\operatorname{Pr}(>|\mathbf{t}|)$ \\
\hline Orth Intercept & 20.964 & 6.584 & 3.184 & 0.003 \\
Orth ZAGEGRouP & -7.156 & 5.376 & -1.331 & 0.183 \\
zPPT & -3.360 & 7.040 & -0.477 & 0.637 \\
ZAGEGrouP:ZPPT & -8.050 & 10.746 & -0.749 & 0.454 \\
\hline
\end{tabular}

As random effects, random intercepts for SUBJECT and ITEM are included, as well as by-ITEM random slopes for the effect of $\mathrm{ZPPT}$. Nb. of observations $=4,213$.

TABLE 8 | Lmer model for semantic priming with fixed effects of ZAGEGROUP and zPPT, as well as their interaction.

\begin{tabular}{lcccc}
\hline & Estimate & Std. error & $\boldsymbol{t}$ & $\operatorname{Pr}(>|\mathbf{t}|)$ \\
\hline Sem Intercept & 8.193 & 5.970 & 1.372 & 0.180 \\
Sem ZAGEGrouP & -2.376 & 5.252 & -0.452 & 0.651 \\
ZPPT & -11.296 & 7.153 & -1.579 & 0.124 \\
ZAGEGroup:ZPPT & 2.756 & 10.506 & 0.262 & 0.793 \\
\hline
\end{tabular}

As random effects, random intercepts for SUBJECT and ITEM are included, as well as by-ITEM random slopes for the effect of $\mathrm{ZPPT}$. Nb. of observations $=4,147$.

The second model for orthographic priming (Table 7) revealed an average priming effect of $20.96 \mathrm{~ms}$, which was significantly different from $0(t=3.184 ; p=0.003)$. Unlike morphological priming, orthographic priming was not affected by ZAgeGroup $(p>0.18)$. Lastly, a model for semantic priming (Table 8) showed that the priming effect of $8.193 \mathrm{~ms}$ was not significantly different from $0(p>0.18)$ and was not modulated by age $(p>0.65)$. Again, this result is exactly what we found when running models on original RT data for orthographic and semantic priming vs. their controls. In contrast to the morphological priming comparison, no main effects for orthography or semantics nor significant priming by age group interactions were observed ( $p$ 's $>0.2$ ).

\section{DISCUSSION}

Our study extends priming paradigms to a less studied language (French) and to a population of healthy aging adults, in order to evaluate the effect of aging on morphological, orthographic, and semantic representation of words. Our experimental design differs from previous approaches in several important ways. First, we used the exact same target words in all six priming conditions and meticulously matched the primes on psycholinguistic properties (e.g., in terms of orthographic prime-target overlap between orthographic and morphological conditions). Secondly, we used inflectional rather than derivational morphology conditions - thereby better controlling for semantic overlapas well as synonyms or troponyms as semantic primes. Third, we employed a "sandwich masking" technique that is known to suppress semantic priming (at least at short PPTs), allowing us to focus on the nature of morphological priming and its relationship to orthographic priming in the absence of semantic contributions. Fourth, we manipulated PPT at three levels $(33,66$, and $150 \mathrm{~ms})$. To our knowledge, this is the first study of healthy aging to investigate inflectional morphological processing with this type of design. Overall, our findings suggest that inflectional morphological priming can facilitate lexical processing in older adults, but that this effect is not the same as that observed in younger adults, as it seems to have weakened to the extent that it is numerically indistinguishable from orthographic priming. As we will discuss below, this result reaches beyond the area of cognitive aging, because it has general implications for morphological processing in psycholinguistic research.

\section{General Aging Effects on Performance}

Our data provide support for the hypothesis that, while aging slows lexical decision responses, it does not negatively affect accuracy (Lima et al., 1991; Madden, 1992; Myerson et al., 1992; Cohen-Shikora and Balota, 2016; Robert and Rico Duarte, 2016; Reifegerste et al., 2018). In fact, accuracy rates on the task were significantly higher in older than younger adults. Furthermore, younger adults showed more variability than older participants, with larger standard deviations for target recognition. These findings are consistent with previous studies showing that older adults perform at ceiling in lexical decision tasks with response accuracies comparable with, or even better than, younger adults (Lima et al., 1991; Madden, 1992; Myerson et al., 1992; CohenShikora and Balota, 2016; Robert and Rico Duarte, 2016). On the other hand, and consistent with previous reports, older adults were generally slower than younger adults (by $102 \mathrm{~ms}$ on average in our study, also consistent with previous research, e.g., Ober and Shenaut, 2014; Curzietti et al., 2017). In order to determine if this significant difference was simply due to prolonged motor response execution (Falkenstein et al., 2006) or related to the specific psycholinguistic task, we also collected $\mathrm{X}$-test data targeting pure motor planning and execution. We found that the aging-related slowing for lexical decision was above and beyond that of behavioral motor responses on the $\mathrm{X}$-test, which were on average $42 \mathrm{~ms}$ slower in older adults as compared to younger participants. Assessing motor responses separately-as we did using the X-test-seems crucial to tease apart age effects on cognitive vs. motor behavior, and to avoid misinterpretations. Our data suggest that higher age increased the duration of cognitive processes involved in the lexical decision task by some $60 \mathrm{~ms}$, i.e., aging appears to have affected cognition even more than motor control. A number of 
mechanisms accounting for these rather general (i.e., conditionindependent) aging effects have been discussed in the literature. On the one hand, the frequent finding of longer processing times and higher performance accuracy in older adults has been described as a "time-accuracy tradeoff," potentially suggesting that older participants may be more cautious, and value correct responses more highly than fast ones (e.g., Ratcliff et al., 2000). In other words, longer response times in older participantsonce corrected for rather trivial motor components-may reflect distinct processing preferences (accuracy over speed), not cognitive decline. However, this interpretation has not found consistent support in the literature (Kliegl et al., 1994; Myerson et al., 2003), which instead points to a rather complex pattern of (neuro-)cognitive aging effects (Hedden and Gabrieli, 2004). According to some authors, cognitive slowing in aging studies on lexical processing such as ours may reflect specific difficulties in orthographic stimuli processing, rather than general lexical access difficulties (Allen et al., 2002) or word representation deterioration. In fact, according to the "decision complexity advantage" hypothesis, older adults rely on progressively larger perceptual units in the attempt to compensate for their difficulties in encoding smaller orthographic units when processing visually presented words (Allen et al., 1993, 2002, 2011). However, given the lack of age effects on orthographic priming in our study, these differences in processing do not appear to be universal and may be linked to the specific conditions that Allen et al. tested (e.g., case manipulation within the word, e.g., TarGEt, or adding spaces between letters).

\section{Lexical Priming and Aging Effects}

Apart from the general age group differences discussed above, we observed significant modulations of accuracy levels in different priming conditions. However, differences were minimal between all conditions ( $2 \%$, on average), and overall performance was near ceiling in older adults. Across age groups, both orthographic and morphological primes improved performance accuracy compared to unprimed controls, while no such effect was found for semantic primes. The lack of semantic priming was expected and, in fact, intended. Recall that we employed a masked priming technique known to suppress semantic priming, in order to test the "eliminativist" hypothesis that morphological priming can be reduced to a combination of semantic and orthographic priming (Bates and Goodman, 1997; Seidenberg and Gonnerman, 2000; Devlin et al., 2004). From this perspective, if semantic priming was successfully suppressed, morphological priming should be indistinguishable from orthographic priming. Accuracy data in both groups were clearly in line with this prediction. However, as in most priming studies with near-ceiling performance levels, the more revealing results were expected to come from RT data.

Surprisingly, even our longest PPT $(150 \mathrm{~ms})$ did not lead to significant semantic priming on RT data. Semantic priming has been reported in different priming paradigms using lexical processing (Balota and Duchek, 1988; Laver and Burk, 1993, for a meta-analysis see Feldman and Prostko, 2002; Giffard et al., 2003), and multimodal cross-modality priming (auditory-visual, Vallet et al., 2013). It must be pointed out, however, that the vast majority of these studies employed long SOAs (i.e., > $200 \mathrm{~ms}$ ) and no masking. Feldman and Prostko (2002) found semantic priming at PPTs of 116 and $300 \mathrm{~ms}$, and so we expected to see a significant effect at a PPT of $150 \mathrm{~ms}$. The absence of this effect (and of PPT modulations of priming effects in general) suggests that masked priming is more powerful in suppressing semantic priming than we originally anticipated. This was also confirmed by Quémart et al. (2011), who found semantic priming with prime masking only at a PPT of $800 \mathrm{~ms}$ (no adults were tested on this PPT). In hindsight, knowing now that, with sandwich masking, much longer PPTs are necessary for semantic priming, we believe using PPTs beyond $250 \mathrm{~ms}$ would have been necessary for it to emerge. It is conceivable that even with masking, semantic priming can occur when participants are asked to attend to the prime. In fact, semantic priming effects from behavioral and ERP studies have been argued by a number of researchers to be driven by factors such as directed attention to the prime, or strategic processing based on partial prime perception, e.g., letters (Abrams and Greenwald, 2000; Klinger et al., 2000; Kiefer and Brendel, 2006; Kouider and Dehaene, 2007; Kouider and Dupoux, 2007). In our study, participants performed on a lexical decision task, that is they were focused on the target and not the prime.

Response time data were found to be modulated by our prime types as well as age, resulting in a more complex pattern than that provided by our accuracy data. Specifically, morphological priming led to significantly reduced reaction times in both young $(34 \mathrm{~ms})$ and older $(19 \mathrm{~ms})$ adults, and the difference in magnitude of this effect between young and older adults (15 ms) was also found to be significant. As expected, there was no indication of semantic priming in either group, and the difference between (non-significant) semantic and (significant) morphological priming itself was significant across both groups.

For the orthographic priming condition, the results were less clear. Overall, the magnitude to which orthographic primes reduced response times on the target word $(20 \mathrm{~ms})$ was between the priming effects for morphology $(27 \mathrm{~ms})$ and those for semantics $(8 \mathrm{~ms})$. Depending on the statistical model, orthographic priming seemed to pattern either with the (significant) morphological priming effect (Table 4) or with the (non-significant) semantic priming effect (Table 5). Similarly, whether the difference in orthographic priming of $7 \mathrm{~ms}$ between young $(24 \mathrm{~ms})$ and older participants $(17 \mathrm{~ms})$ should be viewed as statistically significant (in line with the morphological condition) or as non-significant (in line with the semantic condition), partly depended on the reference condition in the model. An additional analysis focusing exclusively on the orthographic priming condition indicated that this priming effect (i) was clearly significant $(p=0.003)$, but (ii) did not differ between age groups ( $p=0.183$ ). In other words, whereas orthographic priming remains robust with increasing age, morphological primingwhich at a young age is significantly stronger than orthographic priming-becomes weaker and virtually indistinguishable from orthographic priming.

Perhaps the most crucial question concerns the status of orthographic priming in relation to morphological priming. Recall that an eliminativist perspective would predict that, in the absence of any semantic priming, morphological priming 
should be entirely driven by orthographic priming. Since orthographic overlap between prime and target was meticulously matched between these two conditions, one would expect virtually identical priming effects. On the other hand, if the patterns for morphological priming can be shown to be different from orthographic priming, this would support the common assumption that morphology must be viewed as a distinct level of psycholinguistic representation and processing (Stockall and Marantz, 2006; Aronoff and Fudemann, 2011; Amenta and Crepaldi, 2012). Unfortunately, as discussed above, the various statistical analyses of our data did not warrant an unambiguous conclusion as to whether morphological priming effects in our study can be fully attributed to orthographic priming or should rather be viewed as distinct. However, we believe that taking other analyses and data into account ultimately favors the latter perspective. First, recall that the morphological priming condition resulted in a significantly larger effect in young compared to older adults, a group difference absent in the orthographic condition. This pattern is rather unexpected if we assume that both conditions rely on the exact same mechanism (i.e., orthographic priming), but would be expected if they differed qualitatively from each other. Additional evidence that the two conditions of our study involve distinct priming mechanisms (at least in young adults) comes from our previous ERP study (Royle et al., 2012), which used the exact same stimuli and the same "sandwich-masking" technique as the present one. In that study, even though morphological and orthographic priming conditions showed similar accuracy rates (in line with our present data), significant differences in the ERP patterns clearly demonstrated distinct underlying neurocognitive mechanisms. Importantly, the orthographic condition only showed ERP effects during an early time window (N250) known to reflect formal (orthographic/phonological) priming, whereas the morphological condition also affected subsequent lexical processing stages (reflected by the N400). The semantic condition did not show either behavioral or ERP priming effects (in line with the present study). Since both the population (young adults aged 18-35 years) and the PPT of some $50 \mathrm{~ms}$ were comparable to the present study, there is little reason to assume that the underlying cognitive mechanisms should differ between that study and our present group of young adults.

Secondly, if we assume that-in absence of any semantic priming-morphological priming is the same as orthographic priming and linked to orthographic feature overlap (the eliminativist view), any variability among either subjects or items should be comparable for the two conditions. Alternatively, if both rely on distinct mechanisms, no such relationship is expected. We pursued this logic by correlating priming effects across items and participants. Our initial set of correlations tested if those participants in our study who showed the strongest morphological priming were also the ones who showed the strongest orthographic priming. Neither within nor across groups did we find any significant effects supporting this hypothesis (all $p$ values $>0.45$ ). The second set of analyses ran the corresponding correlations across items, which was feasible because the same target words were used in all conditions. What we found was that items showing the strongest morphological priming were not those with the strongest orthographic priming, and vice versa. On the contrary, we observed a negative correlation between these two priming effects: $r^{2}=-0.38, t_{(31)}-2.31, p=0.02$, two-tailed. These same negative correlations were found within younger adults when analyzed alone $\left(r^{2}=0.42, t_{(31)}-2.56, p=0.015\right)$, while no significant correlation was observed in the older group $\left(r^{2}=-0.23, t_{(31)}-1.34, p>0.1\right)$. This is exactly the pattern one would expect, if (a) morphological priming is different from orthographic priming, and (b) morphological priming is stronger (or more prevalent) in young compared to older adults. Even though these results should not be taken as conclusive evidence for a distinct morphological priming mechanism, they are difficult to explain from an eliminativist perspective.

If we assume that morphological priming in young adults was indeed distinct from orthographic priming, a followup question concerns whether the priming effect we see in the morphological condition for older adults is still distinct from orthographic priming in that group. On the one hand, one could argue that morphological priming in young adults consists of orthographic priming plus "true" morphological priming. This interpretation appears to be in line with the ERP findings in Royle et al.'s (2012) study. If morphological priming effects in older adults are reduced to the levels of orthographic priming, then all that remains may be orthographic priming, i.e., "true" morphological priming is lost with aging. Alternatively, it is conceivable that, despite the same magnitude of effects, both types of priming are still qualitatively different. In this case, "true" morphological priming would be at least partly preserved. Our current analyses focusing on behavioral data alone are insufficient to distinguish between these two options. ERP data would certainly provide insight and complimentary data to accuracy and response-time data as to what the cognitive underpinnings for morphological and orthographic processing in aging are. For example, Royle et al. (2012) found similar accuracy for both orthographic and morphological priming but different ERP patterns, and MorganShort et al. (2012) demonstrated that explicit and implicit second-language learners relied on distinct neurocognitive mechanisms to process L2 grammar while behavioral patterns were indistinguishable. Applied to our present data, we can make clear predictions of what types of priming effects we would observe in neurocognitive ERP responses for older vs. younger adults. With masked priming and short PPTs, we expect semantic priming to have lesser or no effects on ERPs in older participants, similar to what has already been shown in younger adults. Orthographic priming should modulate the N250, as with younger adults. However, morphological priming could result in two different scenarios. Under the assumption that morphological priming is entirely carried by orthographic priming in older adults, only the N250 should be modulated by morphological priming. However, if we assume that morphological processing is still present although weaker in older adults, both the N250 and the N400 should be modulated by morphological priming, similar to young adults but to a lesser extent. Thus, behavioral and ERP approaches together provide 
complimentary information on language processing: while ERPs can tease apart the time-course of different processing stages, behavioral approaches allow for complex designs involving different prime-presentation manipulations, which in turn can help us define ideal manipulations for more constrained ERP experimental designs.

The facilitatory effect of morphological priming on lexical decision in our sample of young adults replicates Quémart et al's (2011) findings showing that that both French-speaking children and young adults take advantage of morphological priming. Similarly, Jacob et al. (2018) find that, in young adult German-speakers, inflectional and derivational morphology priming results in speeded reaction times as compared to a control condition, but that orthographic and semantic priming do not. This is also consistent with a recent ERP study on late-second-language learners demonstrating that morphological priming boosts word recognition in French learners, independent of learning level (Coughlin et al., 2019), and with previous ERP data showing significantly different modulation of early and late components for lexical processing with the same stimuli as ours, that is weak effects of orthographic priming, strong and longer-lasting effects of morphological priming and no semantic priming (Royle et al., 2012).

Our results critically expand previous research in the field of morphological processing and aging by demonstrating that regular-inflection morphological priming is lesser in older adults than younger ones, in contrast to what has been found in German by Reifegerste et al. (2018), who find equivalent regular inflection priming effects in younger and older participants. In line with the rare inflection morphology production studies (MacKay and James, 2004; Moscoso Del Prado Martín, 2017), we show that morphological processing might also be somewhat impaired in comprehension. However, our results do not provide evidence for formal (phonological/orthographic) difficulties in aging, contrary to MacKay and James (2004). We can reconcile the apparently contradictory data by proposing that morphological representation is available but weaker in older vs. younger adults. However, studies showing age effects on inflection morphology engaged older adults in complex language production tasks, which might be an additional source of difficulty. Based on our present data, the claim that morphological processing is not affected by aging (e.g., Reifegerste et al., 2018) might be an overgeneralization.

\section{CONCLUSION}

In conclusion, our study suggests that morphological word representation is not stable over the lifespan, and that this effect is independent from semantic abilities, but its relationship to orthographic processing remains unclear. Older adults showed regular inflection morphological priming at similar levels to orthographic priming, and no semantic priming. This indicates that inflectional morphological processing is possibly maintained and relatively efficient in the older population, and that whatever this effect is it is not an epiphenomenon of semantic processing, while orthographic processing is maintained over the lifespan. This is a crucial result that allows us to better define the nature of potential language processing difficulties in older adults. Because some studies show that morphological and phonological production in spoken language can be difficult in aging adults, the source of these difficulties has yet to be clearly identified. Future studies should focus on how morphological word representation interacts with other cognitive and language domains, in order to better understand morphological errors that are sometimes observed in speech production in older adults, for example. Complimentary ERP studies of aging might shed light neurocognitive mechanisms underlying morphological processing across the lifespan.

\section{ETHICS STATEMENT}

Participants received 40\$CAD for their participation and signed informed consent to participate. The Project was approved by the ethics committees of the Université de Montréal, and the Centre de recherche de l'Institut Universitaire de Gériatrie de Montréal (CRIUGM).

\section{AUTHOR CONTRIBUTIONS}

PR: study conception, statistical analyses, manuscript development, data interpretation. KS: study conception, data analysis, data interpretation. ÉD: participant recruitment, data collection, data management, research report, and preliminary analyses. $\mathrm{ACH}$ : statistical analyses. SMB: theoretical aspects of aging, experiment programming, participant recruitment, lab supervision, manuscript development. All authors participated in manuscript writing and revision.

\section{FUNDING}

This project was supported by Université de Montréal seed funding to PR, Subvention Institutionnelle du CRSH, UdeM (\# R0014537), an SSHRC Insight grant (\# 435-2013-2052) to KS and PR, a CRBLM Research incubator award (2012) to PR, SMB, Gonnerman, and KS, an SSHRC Partnership Grant to Libben et al (\# 895-2016-1008), and two summer bursary undergraduate scholarships from the Faculty of Medicine of the University of Montreal (COPSE) (2013-2014) to ÉD.

\section{ACKNOWLEDGMENTS}

We thank participants who volunteered for this project and Cynthia Sarkis for help with data management.

\section{SUPPLEMENTARY MATERIAL}

The Supplementary Material for this article can be found online at: https://www.frontiersin.org/articles/10.3389/fcomm. 2019.00016/full\#supplementary-material 


\section{REFERENCES}

Abrams, R. L., and Greenwald, A. G. (2000). Parts outweigh the whole (word) in unconscious analysis of meaning. Psychol. Sci. 11, 118-124. doi: $10.1111 / 1467-9280.00226$

Alegre, M., and Gordon, P. (1999). Rule-based versus associative processes in derivational morphology. Brain Lang. 68, 347-354. doi: 10.1006/brln. 1999.2066

Allen, P. A., Bucur, B., Grabbe, J., Work, T., and Madden, D. J. (2011). Influence of encoding difficulty, word frequency, and phonological regularity on age differences in word naming. Exp. Aging Res. 37, 261-292. doi: 10.1080/0361073X.2011.568805

Allen, P. A., Lien, M. C., Murphy, M. D., Sanders, R. E., Judge, K. S., and McCann, R. S. (2002). Age differences in overlapping-task performance: evidence for efficient parallel processing in older adults. Psychol. Aging 17, 505-519. doi: 10.1037//0882-7974.17.3.505

Allen, P. A., Madden, D. J., Weber, T. A., and Groth, K. E. (1993). Influence of age and processing stage on visual word recognition. Psychol. Aging 8, 274-282. doi: 10.1037//0882-7974.8.2.274

Amenta, S., and Crepaldi, D. (2012). Morphological processing as we know it: an analytical review of morphological effects in visual word identification. Front. Psychol. 3:232. doi: 10.3389/fpsyg.2012.00232

Ansaldo, J., Marsolais, Y., Methqal, I., Alary, F., and Joanette, Y. (2013). The adaptive aging brain: evidence from the preservation of communication abilities with age. Eur. J. Neurosci. 37, 1887-1895. doi: 10.1111/ejn.12252

Aronoff, M., and Fudemann, K. (2011). What Is Morphology? Oxford: Wiley-Blac.

Baayen, R. H., Milin, P., Đurdević, D. F., Hendrix, P., and Marelli, M. (2011). An amorphous model for morphological processing in visual comprehension based on naive discriminative learning. Psychol. Rev. 118, 438. doi: 10.1037/a0023851

Balota, D. A., and Duchek, J. M. (1988). Age-related differences in lexical access, spreading activation, and simple pronunciation. Psychol. Aging 3, 84-93. doi: $10.1037 / 0882-7974.3 .1 .84$

Barr, D. J., Levy, R., Scheepers, C., and Tily, H. J. (2013). Random effects structure for confirmatory hypothesis testing: keep it maximal. J. Mem. Lang. 68, 255-278. doi: 10.1016/j.jml.2012.11.001

Bates, D., Mäechler, M., Bolker, B., and Walker, S. (2015). Fitting linear mixedeffects models using lme4. J. Stat. Softw. 67, 1-48. doi: 10.18637/jss.v067.i01

Bates, E., and Goodman, J. C. (1997). On the inseparability of grammar and the lexicon: evidence from acquisition, aphasia and real-time processing. Lang. Cogn. Process. 12, 507-584. doi: 10.1080/016909697386628

Bertram, R., Laine, M., and Virkkala, M. M. (2001). The role of derivational morphology in vocabulary acquisition: get by with a little help from my morpheme friends. Scand. J. Psychol. 41, 287-296. doi: $10.1111 / 1467-9450.00201$

Bijeljac-Babic, R., Biardeau, A., and Grainger, J. (1997). Masked orthographic priming in bilingual word recognition. Mem. Cognit. 25, 447-457. doi: 10.3758/BF03201121

Bowles, N. L., and Poon, L. W. (1985). Aging and retrieval of words in semantic memory. J. Gerontol. 40, 71-77. doi: 10.1093/geronj/40.1.71

Brown, C., and Hagoort, P. (1993). The processing nature of the N400: evidence from masked priming. J. Cognit. Neurosci. 51, 34-44. doi: 10.1162/jocn.1993.5.1.34

Burke, D. M. (1997). Language, aging, and inhibitory deficits: evaluation of a theory. J. Gerontol. B. Psychol. Sci. Soc. Sci. 52, P254-P264. doi: 10.1093/geronb/52B.6.P254

Chapleau, M., Wilson, M. A., Potvin, K., Harvey-Langton, A., Montembeault, M., and Brambati, S. M. (2017). Word reading aloud skills: their positive redefinition through ageing. J. Res. Read. 40, 297-312. doi: 10.1111/1467-9817.12065

Clahsen, H., and Reifegerste, J. (2017). "Morphological processing in oldage bilinguals," in Bilingualism: A Framework for Understanding the Mental Lexicon, eds M. Libben, M. Goral, and G. Libben (Amsterdam: Benjamins), 217-248.

Cohen-Shikora, E. R., and Balota, D. A. (2016). Visual word recognition across the adult lifespan. Psychol. Aging 31, 488-502. doi: 10.1037/pag00 00100
Connor, L. T., Spiro, A., Obler, L. K., and Albert, M. L. (2004). Change in object naming ability during adulthood. J. Gerontol. B 59, P203-P209. doi: 10.1093/geronb/59.5.P203

Coughlin, C., Fiorentino, R., Royle, P., and Steinhauer, K. (2019). Sensitivity to inflectional morphology in a non-native language: evidence from ERPs. Front. Comm. 5: 888. doi: 10.3389/fcomm.2019.00021. [Epub ahead of print].

Curzietti, M., Bonnefond, A., Staub, B., Vidailhet, P., and Doignon-Camus, N. (2017). The effects of age on visual expertise for print. Brain Lang. 169, 48-56. doi: 10.1016/j.bandl.2017.03.001

Deacon, D., Hewitt, S., Yang, C.-M., and Nagata, M. (2000). Event-related potential indices of semantic priming using masked and unmasked words: evidence that the N400 does not reflect a post-lexical process. Cogn. Brain Res. 9, 137-146. doi: 10.1016/S0926-6410(99)00050-6

Derouesné, C., Poitreneau, J., Hugonot, L., Kalafat, M., Dubois, B., and Laurent, B. (1999). Le Mini-Mental State Examination (MMSE): un outil pratique pour l'évaluation de l'état cognitif des patients par le clinicien. Version française consensuelle [The Mini-mental State Examination (MMSE): a practical method for grading the cognitive state of patients for the clinician. Consensual French version]. Presse Méd. 28, 1141-1148. Available online at: https://docobook.com/ le-mini-mental-state-examination-mm-s-e-un-outil.html

Devlin, J. T., Jamison, H. L., Matthews, P. M., and Gonnerman, L. M. (2004). Morphology and the internal structure of words. Proc. Natl. Acad. Sci. U.S.A. 101, 14984-14988. doi: 10.1073/pnas.0403766101

Duñabeitia, J. A., Perea, M., and Carreiras, M. (2009). Masked translation priming effects with highly proficient simultaneous bilinguals. Exp. Psychol. 57, 98-107. doi: 10.1027/1618-3169/a000013

Falkenstein, M., Yordanova, J., and Kolev, V. (2006). Effects of aging on slowing of motor-response generation. Int. J. Psychophysiol. 59, 22-29. doi: 10.1016/j.ijpsycho.2005.08.004

Feldman, L. B., and Prostko, B. (2002). Graded aspects of morphological processing: task and processing time. Brain Lang. 81, 12-27. doi: $10.1006 /$ brln.2001.2503

Feyereisen, P. (1997). A meta-analytic procedure shows an age-related decline in picture naming: comments on Goulet, Ska, and Kahn (1994). J. Speech Lang. Hear. Res. 40, 1328-1333. doi: 10.1044/jslhr.4006.1328

Fjell, A. M., Westlye, L. T., Grydeland, H., Amlien, I., Espeseth, T., Reinvang, I., et al. (2013). Critical ages in the life course of the adult brain: nonlinear subcortical aging. Neurobiol. Aging 34, 2239-2247. doi: 10.1016/j.neurobiolaging.2013.04.006

Folstein, M. F., Folstein, S. E., and McHugh, P. R. (1975). "Mini-mental state": a practical method for grading the cognitive state of patients for the clinician. $J$. Psychiatr. Res. 12, 189-198. doi: 10.1016/0022-3956(75)90026-6

Forster, K. I. (1998). The pros and cons of masked priming. J. Psycholinguist. Res. 2, 203-233. doi: 10.1023/A:1023202116609

Fox, J., and Weisberg, S. (2011). An R Companion to Applied Regression. R Package Version (Thousand Oaks, CA: Sage), 2.0-19.

Frauenfelder, U. H., and Schreuder, R. (1992). "Constraining psycholinguistic models of morphological processing and representation: The role of productivity," in Yearbook of Morphology, eds G. Booij and J. van Merle (Dordrecht: Kluwer), 165-183.

Gelman, A., and Su, Y.-S. (2018). arm: Data Analysis Using Regression and Multilevel/Hierarchical Models. R package version 1.10-1. Available online at: https://CRAN.R-project.org/package=arm.

Giffard, B., Desgranges, B., Kerrouche, N., Piolino, P., and Eustache, F. (2003). The hyperpriming phenomenon in normal aging: a consequence of cognitive slowing? Neuropsychology 17, 594-601. doi: 10.1037/0894-4105.17.4.594

Good, C. D., Johnsrude, I. S., Ashburner, J., Henson, R. N., Friston, K. J., and Frackowiak, R. S. (2001). A voxel-based morphometric study of ageing in 465 normal adult human brains. Neuroimage 14, 21-36. doi: 10.1006/nimg.2001.0786

Gordon, J. K., and Kurczek, J. C. (2014). The aging neighborhood: phonological density in naming. Lang. Cogn. Process. 29, 326-344. doi: 10.1080/01690965.2013.837495

Grieder, M., Crinelli, R. M., Koenig, T., Wahlund, L.-O., Dierks, T., and Wirth, M. (2012). Electrophysiological and behavioral correlates of stable automatic semantic retrieval in aging. Neuropsychologia 50, 160-171. doi: 10.1016/j.neuropsychologia.2011.11.014 
Hedden, T., and Gabrieli, J. D. (2004). Insights into the ageing mind: a view from cognitive neuroscience. Nat. Rev. Neurosci. 5, 87-96. doi: 10.1038/nrn1323

Jacob, G., Heyer, V., and Veríssimo, J. (2018). Aiming at the same target: a masked priming study directly comparing derivation and inflection in the second language. Int. J Bilingual. 22, 619-637. doi: 10.1177/1367006916688333

James, L. E., and Burke, D. M. (2000). Phonological priming effects on word retrieval and tip-of-the-tongue experiences in young and older adults. J. Exp. Psychol. Learn. Mem. Cogn. 26, 1378-1391. doi: 10.1037//0278-7393.26.6.137

Kavé, G., and Goral, M. (2017). Do age-related word retrieval difficulties appear (or disappear) in connected speech? Neuropsychol. Dev. Cogn. B Aging Neuropsychol. Cogn. 24, 508-527. doi: 10.1080/13825585.2016.1226249

Kemper, S., Thompson, M., and Marquis, J. (2001). Longitudinal change in language production: effects of aging and dementia on grammatical complexity and propositional content. Psychol. Aging 16, 600-614. doi: $10.1037 / / 0882-7974.16 .4 .600$

Kiefer, M., and Brendel, D. (2006). Attentional modulation of unconscious "automatic" processes: evidence from event-related potentials in a masked priming paradigm. J. Cogn. Neurosci. 18, 184-198. doi: $10.1162 / 089892906775783688$

Kliegl, R., Mayr, U., and Krampe, R. T. (1994). Time-accuracy functions for determining process and person differences: an application to cognitive aging. Cognitive Psychol. 26, 134-164. doi: 10.1006/cogp.1994.1005

Klinger, M. R., Burton, P. C., and Pitts, G. S. (2000). Mechanisms of unconscious priming: I. Response competition not spreading activation. J. Exp. Psych. Learn. Mem. Cogn. 26, 441-455. doi: 10.1037/0278-7393.26.2.441

Kouider, S., and Dehaene, S. (2007). Levels of processing during non-conscious perception: a critical review of visual masking. Phil. Trans. R. Soc. B 362, 857-875. doi: 10.1098/rstb.2007.2093

Kouider, S., and Dupoux, E. (2007). Partial awareness creates the "illusion" of subliminal semantic priming. Psychol. Sci. 15, 75-81. doi: 10.1111/j.0963-7214.2004.01502001.x

Laver, G. D., and Burk, D. M. (1993). Why do semantic priming effects increase in old age? A meta-analysis. Psychol. Aging 8, 34-43. doi: 10.1037/0882-7974.8.1.34

Lenth, R. (2018). Emmeans: Estimated Marginal Means, Aka Least-Squares Means. $\mathrm{R}$ package version 1.3.0. Available online at: https://CRAN.R-project.org/ package $=$ emmeans.

Lima, S. D., Hale, S., and Myerson, J. (1991). How general is general slowing? Evidence from the lexical domain. Psychol. Aging 6, 416-425. doi: 10.1037/0882-7974.6.3.416

Lindemer, E. R., Greve, D. N., Fischl, B. R., Augustinack, J. C., and Salat, D. H. (2017). Regional staging of white matter signal abnormalities in aging and Alzheimer's disease. Neuroimage Clin. 14, 156-165. doi: 10.1016/j.nicl.2017.01.022

Lüdecke, D. (2017). Sjstats: Statistical Functions for Regression Models. R package version 0.10.2. Available online at: https://CRAN.R-project.org/package= sjstats.

Lustig, C., and Buckner, R. L. (2004). Preserved neural correlates of priming in old age and dementia. Neuron 42, 865-875. doi: 10.1016/j.neuron.2004.04.002

MacKay, D. G., and James, L. E. (2004). Sequencing, speech production, and selective effects of aging on phonological and morphological speech errors. Psychol. Aging 19, 93-107. doi: 10.1037/0882-7974.19.1.93

Madden, D. J. (1992). Four to ten milliseconds per year: age-related slowing of visual word identification. J. Gerontol. 47, P59-P68. doi: 10.1093/geronj/47.2.P59

Madden, D. J., Pierce, T. W., and Allen, P. A. (1993). Age-related slowing and the time course of semantic priming in visual word identification. Psychol. Aging 8, 490-507. doi: 10.1037//0882-7974.8.4.490

Marquis, A., and Royle, P. (2019). "Verb acquisition in monolingual and multilingual children and adults," in Proceedings of the GALA: Language Acquisition and Development, eds P. Guijarro-Fuentes and C. Suárez-Gómez (Newcastle upon Tyne: Cambridge Scholars Publishing), 307-324.

McKoon, G., and Ratcliff, R. (1995). Conceptual combinations and relational contexts in free association and in priming lexical decision and naming. Psychon. Bull. Rev. 2, 527-533. doi: 10.3758/BF03210988

Meunier, F., and Longtin, C.-M. (2007). Morphological decomposition and semantic integration in word processing. J. Mem. Lang. 56, 457-471. doi: 10.1016/j.jml.2006.11.005
Milin, P., Divjak, D., and Baayen, R. H. (2017). A learning perspective on individual differences in skilled reading: exploring and exploiting orthographic and semantic discrimination cues. J. Exp. Psychol. Learn. Mem. Cogn. 43, 1730-1751. doi: 10.1037/xlm0000410

Montembeault, M., Joubert, S., Doyon, J., Carrier, J., Gagnon, J.-F., Monchi, O., et al. (2012). The impact of aging on gray matter structural covariance networks. Neuroimage 63, 754-759. doi: 10.1016/j.neuroimage.2012. 06.052

Morgan-Short, K., Steinhauer, K., Sanz, C., and Ullman, M. T. (2012). Explicit and implicit second language training differentially affect the achievement of native-like brain activation patterns. J. Cogn. Neurosci. 24, 933-947. doi: 10.1162/jocn_a_00119

Moscoso Del Prado Martín, F. (2017). Vocabulary, grammar, sex, and aging. Cogn. Sci. 41, 950-975. doi: 10.1111/cogs.12367

Murray, L. L. (2000). The effects of varying attentional demands on the word retrieval skills of adults with aphasia, right hemisphere brain damage, or no brain damage. Brain Lang. 72, 40-72. doi: 10.1006/brln.1999.2281

Myerson, J., Adams, D. R., Hale, S., and Jenkins, L. (2003). Analysis of group differences in processing speed: brinley plots, Q-Q plots, and other conspiracies. Psychon. Bull. Rev. 10, 224-237. doi: 10.3758/BF031 96489

Myerson, J., Ferraro, F. R., Hale, S., and Lima, S. D. (1992). General slowing in semantic priming and word recognition. Psychol. Aging 7, 257-270.

Nasreddine, Z. S., Phillips, N. A., Bédirian, V., Charbonneau, S., Whitehead, V., Collin, I., et al. (2005). The Montreal Cognitive Assessment, MoCA: a brief screening tool for mild cognitive impairment. J. Am. Geriatr. Soc. 53, 695-699. doi: 10.1111/j.1532-5415.2005.53221.x

Neely, J. H., Keefe, D. E., and Ross, K. L. (1989). Semantic priming in the lexical decision task: roles of prospective prime-generated expectancies and retrospective semantic matching. J. Exp. Psychol. Learn. Mem. Cogn. 15, 1003-1019. doi: 10.1037/0278-7393.15.6.1003

Ober, B. A., and Shenaut, G. K. (2014). Repetition priming of words and nonwords in Alzheimer's disease and normal aging. Neuropsychology 28, 973-983. doi: 10.1037/neu0000112

Obler, L. K., Rykhlevskaia, E., Schnyer, D., Clark-Cotton, M. R., Spiro, A., Hyun, J., et al. (2010). Bilateral brain regions associated with naming in older adults. Brain Lang. 113, 113-123. doi: 10.1016/j.bandl.2010.03.001

Pacton, S., and Deacon, S. H. (2008). The timing and mechanisms of children's use of morphological information in spelling: a review of evidence from English and French. Cogn. Dev. 23, 339-359. doi: 10.1016/j.cogdev.2007. 09.004

Patterson, K., Nestor, P. J., and Rogers, T. T. (2007). Where do you know what you know? The representation of semantic knowledge in the human brain. Nat. Rev. Neurosci. 8, 976-987. doi: 10.1038/nrn2277

Provost, J.-S., Brambati, S. M., Chapleau, M., and Wilson, M. A. (2016). The effect of aging on the brain network for exception word reading. Cortex 84, 90-100. doi: 10.1016/j.cortex.2016.09.005

Quémart, P., Casalis, S., and Colé, P. (2011). The role of form and meaning in the processing of written morphology: a priming study in French developing readers. J. Exp. Child Psychol. 109, 478-496. doi: 10.1016/j.jecp. 2011.02 .008

Rastle, K., and Davis, M. H. (2008). Morphological decomposition based on the analysis of orthography. Lang. Cogn. Process. 23, 942-971. doi: 10.1080/01690960802069730

Ratcliff, R., Spieler, D., and McKoon, G. (2000). Explicitly modeling the effects of aging on response time. Psychon. B. Rev. 7, 1-25. doi: 10.3758/ BF03210723

Raveh, M., and Rueckl, J. G. (2000). Equivalent effects of inflected and derived primes: long-term morphological priming in fragment completion and lexical decision. J. Mem. Lang. 42, 103-119. doi: 10.1006/jmla.1999.2673

Raz, N., Gunning, F. M., Head, D., Dupuis, J. H., McQuain, J., Briggs, S. D., et al. (1997). Selective aging of the human cerebral cortex observed in vivo: differential vulnerability of the prefrontal gray matter. Cereb. Cortex N. Y. 7, 268-282. doi: 10.1093/cercor/7.3.268

Raz, N., Gunning-Dixon, F., Head, D., Rodrigue, K. M., Williamson, A., and Acker, J. D. (2004). Aging, sexual dimorphism, and hemispheric asymmetry of the cerebral cortex: replicability of regional differences in volume. Neurobiol. Aging 25, 377-396. doi: 10.1016/S0197-4580(03)00118-0 
Reifegerste, J., and Clahsen, H. (2017). Accessing morphosyntactic information is preserved at old age, except for irregulars. Ment. Lex. 12, 342-372. doi: $10.1075 / \mathrm{ml} .17008$.rei

Reifegerste, J., Elin, K., and Clahsen, H. (2018). Persistent differences between native speakers and bilinguals: evidence from inflectional and derivational processing in older speakers. Bilingualism 22, 425-440. doi: $10.1017 /$ S1366728918000615

Robert, C., and Rico Duarte, L. (2016). Semantic richness and aging: the effect of number of features in the lexical decision task. J. Psycholinguist. Res. 45, 359-365. doi: 10.1007/s10936-015-9352-8

Roelofs, A., and Piai, V. (2011). Attention demands of spoken word planning: a review. Front. Psychol. 2:307. doi: 10.3389/fpsyg.2011.00307

Royle, P., Drury, J. E., Bourguignon, N., and Steinhauer, K. (2012). The temporal dynamics of inflected word recognition: a masked ERP priming study of French verbs. Neuropsychologia 50, 3542-3553. doi: 10.1016/j.neuropsychologia.2012.09.007

Rvachew, S., Royle, P., Gonnerman, L. M., Stanké, B., Marquis, A., and Herbay, A. (2017). Development of a tool to screen risk of literacy delays in French-speaking children: PHOPHLO. Can. J. Speech-Lang. Pathol. Audiol. 41, 321-340. Available online at: https://cjslpa.ca/files/2017_CJSLPA_Vol_41/ No_03/CJSLPA_Vol_41_No_3_2017_Rvachew_et_al_321-340.pdf

Seidenberg, M. S., and Gonnerman, L. M. (2000). Explaining derivational morphology as the convergence of codes. Trends Cogn. Sci. 4, 353-361. doi: 10.1016/S1364-6613(00)01515-1

Shewan, C. M., and Henderson, V. L. (1988). Analysis of spontaneous language in the older normal population. J. Commun. Disord. 21, 139-154. doi: 10.1016/0021-9924(88)90002-0

Steinhauer, K., Royle, P., Drury, J. E., and Fromont, L. A. (2017). The priming of priming: evidence that the N400 reflects context dependent post-retrieval word integration in working memory. Neurosci. Lett. 651, 192-197. doi: 10.1016/j.neulet.2017.05.007
Stockall, L., and Marantz, A. (2006). A single route, full decomposition model of morphological complexity: MEG evidence. Ment. Lex. 1, 85-123. doi: $10.1075 / \mathrm{ml} \cdot 1.1 .07$ sto

Sylvain-Roy, S., Lungu, O., and Belleville, S. (2015). Normal aging of the attentional control functions that underlie working memory. J. Gerontol. B. Psychol. Sci. Soc. Sci. 70, 698-708. doi: 10.1093/geronb/gbt166

Vallet, G. T., Simard, M., Versace, R., and Mazza, S. (2013). The perceptual nature of audiovisual interactions for semantic knowledge in young and elderly adults. Acta Psychol. 143, 253-260. doi: 10.1016/j.actpsy.2013. 04.009

Verhaegen, C., and Poncelet, M. (2013). Changes in Naming and Semantic Abilities With Aging From 50 to 90 years. J. Int. Neuropsychol. Soc. 19, 119-126. doi: $10.1017 /$ S1355617712001178

Zec, R. F., Markwell, S. J., Burkett, N. R., and Larsen, D. L. (2005). A longitudinal study of confrontation naming in the "normal" elderly. J. Int. Neuropsychol. Soc. 11, 716-726. doi: 10.1017/S13556177050 50897

Zuccolotto, P. A., Roush, E. R., Eschman, A., and Schneider, W. (2012). E-Prime 2.0. Sharpsburg, PA: Psychology Software Tools, Inc.

Conflict of Interest Statement: The authors declare that the research was conducted in the absence of any commercial or financial relationships that could be construed as a potential conflict of interest.

Copyright (c) 2019 Royle, Steinhauer, Dessureault, Herbay and Brambati. This is an open-access article distributed under the terms of the Creative Commons Attribution License (CC BY). The use, distribution or reproduction in other forums is permitted, provided the original author(s) and the copyright owner(s) are credited and that the original publication in this journal is cited, in accordance with accepted academic practice. No use, distribution or reproduction is permitted which does not comply with these terms. 